\title{
BMJ Open Associations between healthcare worker participation in workplace wellness activities and job satisfaction, occupational stress and burnout: a cross- sectional study in Botswana
}

\author{
Jenny H Ledikwe, ${ }^{1,2}$ Nora Joelle Kleinman, ${ }^{1,2,3}$ Maureen Mpho, ${ }^{4}$ \\ Heather Mothibedi, ${ }^{4}$ Shreshth Mawandia, ${ }^{1,2}$ Bazghina-werq Semo, ${ }^{1,2}$ \\ Gabrielle O’Malley ${ }^{1}$
}

To cite: Ledikwe $\mathrm{JH}$, Kleinman NJ, Mpho M, et al. Associations between healthcare worker participation in workplace wellness activities and job satisfaction, occupational stress and burnout: a cross-sectional study in Botswana. BMJ Open 2018;8:e018492. doi:10.1136/ bmjopen-2017-018492

- Prepublication history for this paper is available online. To view these files, please visit the journal online (http://dx.doi. org/10.1136/bmjopen-2017018492).

Received 3 July 2017 Revised 16 February 2018 Accepted 16 February 2018
Check for updates

${ }^{1}$ Department of Global Health, University of Washington, Seattle, Washington, USA ${ }^{2}$ International Training and Education Center for Health (I-TECH), Gaborone, Botswana ${ }^{3}$ NJK Consulting, Seattle, Washington, USA

${ }^{4}$ Department of HIV/AIDS Prevention and Care, Botswana Ministry of Health, Gaborone, Botswana

Correspondence to Dr Jenny H Ledikwe; ledikwe@uw.edu

\section{ABSTRACT}

Objectives Healthcare workers (HWs) are prone to high levels of stress and burnout, particularly when caring for people with HIV/AIDS. This study assessed whether participation in Botswana's Workplace Wellness Programme (WWP) for HWs was associated with job satisfaction, occupational stress, well-being and burnout. Methods Using multistage sampling, a paper-based questionnaire was distributed to 1856 randomly selected HWs at 135 public facilities across Botswana. Wellvalidated scales assessed key outcomes. Analysis of covariance models were built for psychosocial factors associated with WWP participation, controlling for associated demographics.

Results Response rate was $73 \%(n=1348)$. The majority of respondents were female (62\%), not married (65\%) and had children $(84 \%)$. Mean age was 40.0 years $(\mathrm{SD} \pm 9.9)$. Respondents were roughly split between participation in no WWP activities (29.4\%), 1-6 WWP activities (38.9\%) and seven or more WWP activities (31.7\%) in the past year. High participation was associated with older age, being a doctor or other professional, working at hospitals or District Health Management Teams, working longer in health services or working longer at a facility. In unadjusted analyses, high participation was significantly associated $(P<0.05)$ with higher satisfaction with overall job, work, supervision, promotion, pay and professional efficacy and lower stress, exhaustion and cynicism. All associations remained significant in controlled analyses except cynicism.

Conclusions Results from this study suggest that participation in workplace wellness activities is associated with higher satisfaction with multiple job facets and lower stress, exhaustion and cynicism. Introduction of these activities may help ameliorate high occupational stress levels among HWs.

\section{INTRODUCTION}

Healthcare professionals are prone to high levels of occupational stress. When stress is experienced chronically, it results in burnout, an exhaustion of physical and emotional resources. ${ }^{1}$ This is due to long hours and the
Strengths and limitations of this study

- Strengths include a multilevel random sampling methodology and use of previously validated scales.

- The survey had a relatively high response rate $(73 \%)$.

- Limitations include an inability to determine the direction of causality due to the cross-sectional nature of the survey.

emotional weight of treating sick patients ${ }^{2}$ and is especially common among providers who work with People Living with HIV/ AIDS (PLHA). ${ }^{3}$ In the early years of the HIV epidemic, the stress was primarily due to stigma around the disease, lack of understanding of transmission and treatment and the extremely high mortality rate. ${ }^{4}$ The introduction of highly active antiretroviral therapy and increased community and clinical HIV knowledge has lessened stress on providers. However, many providers still experience stress from the emotional toll of caring for sick patients, workplace demands, lack of supervision, unresolved grief, feelings of helplessness and ineffectiveness and an absence of gratitude from individuals and communities. ${ }^{45}$ Accordingly to the Maslach Burnout Model, this persistent stress eventually results in burnout, composed of 'overwhelming' exhaustion, cynicism and a sense of ineffectiveness. ${ }^{1}$

In sub-Saharan Africa, high demand for services and insufficient resources are still commonplace, resulting in tense environments for health workers involved in HIV treatment, care and support. This situation may be compound by the new Joint United Nations Programme on HIV/AIDS 
(UNAIDS) targets of having 90\% of PLHA know their status, $90 \%$ of people who know they have HIV on antiretroviral (ARV) treatment and 90\% of PLHA on treatment virally suppressed. ${ }^{6}$

Botswana, with an $18.5 \%$ prevalence rate, has been one of the countries most affected by the HIV epidemic. ${ }^{7} \mathrm{~A}$ survey conducted in 2006 indicated there were high levels of stress and burnout among health workers in Botswana, due in part to the rising burden of patients with HIV/ AIDS and the related pressure on the healthcare system. ${ }^{8}$ In response, the Botswana Ministry of Health (MOH) began implementing a comprehensive Workplace Wellness Programme (WWP) for healthcare workers in $2007 .^{9}$ This initiative aimed to improve health and well-being and reduce stress among health workers in government facilities by empowering them with knowledge and skills to manage the dynamic demands of the healthcare system. ${ }^{8}$ WWP implementation has been described previously. ${ }^{10}$ Briefly, the programme focused on holistic improvements in health and well-being through activities focusing on: health screening, treatment and care; health promotion; stress management and team building; occupational health and safety; psychosocial and spiritual care and therapeutic recreation.

Data from high-income settings suggest that WWPs can have numerous benefits, including lowered healthcare costs, reduced absenteeism, increased productivity and positive economic impact. ${ }^{11-15}$ However, the situation is different in less resourced countries, with higher reported levels of anxiety, depression and health risks ${ }^{16}$ and lower nutritional habits and physical activity. ${ }^{17}$ Thus, little is known about the effectiveness of WWPs when implemented to improve occupational health among health workers in these settings, outside of a few studies in South Africa. ${ }^{18-21}$ Therefore, a nationally representative survey of health workers in Botswana was conducted to determine if there were associations between participation in WWP activities with individuals' levels of job satisfaction, psychological well-being, burnout and sources of stress.

\section{METHODS}

This was a cross-sectional survey of staff employed at public health facilities in Botswana. Individuals had to be employed in a selected public health facility to be eligible to participate. A self-administered questionnaire was distributed to randomly selected health workers in public health facilities using multistage sampling. The first sampling stage was to select the health facilities, using a random number generator to select five facilities in each of Botswana's 27 health districts. For each district, one facility was selected from each of the following five types of health facilities: district health management teams, hospitals, clinics with maternity services, clinics without maternity services and health posts. When no facility was available in a particular category, an additional facility was selected at random. If a district had less than five facilities, all were chosen. The second stage of sampling was to select healthcare workers. For each selected facility, employees were categorised according to four cadres: doctors and nurses providing clinical care, administrative personnel (doctors and nurses acting in administrative capacity, human resources staff, data clerks), other professionals (social workers, pharmacists, nutritionists, allied health professionals including radiographers and pharmacist technicians, paraprofessionals including lay counsellors and health education assistants), and support staff (drivers, cleaners, gardeners). Four participants and two alternates were randomly selected per cadre at each facility. If a facility had fewer than four employees in a cadre, all were selected. One district had fewer than five facilities and many cadres had fewer than four people. In total, surveys were distributed to 1856 health workers in 134 facilities (32 clinics with maternity, 29 clinics without maternity, 26 health posts, 26 District Health Management Teams (DHMTs) and 21 health posts), which represents $9.3 \%$ of the estimated 20000 health workers in the country. ${ }^{22}$ This sample size was calculated to provide a confidence level of 95\% and CI of 5\% among the smallest employee category (other professionals, $\mathrm{n}=4751$ ) working at public health facilities.

Surveys were administered by district WWP focal people. To ensure uniform administration, these individuals received a 1-week training including general research topics, research ethics, the survey tool and the distribution process. In rare cases, where a participant had limited literacy and/or English skills, focal people supported completion of the survey. Participants completed the questionnaire, sealed it in an envelope and returned it to the district WWP focal person. Envelopes were sent through government transport, post or courier to the research team in Gaborone.

\section{Questionnaire}

The self-administered questionnaire consisted of quantitative, closed-ended questions assessing demographics (age, gender, marital status, children, education, employment cadre, type of facility, length of time in healthcare, length of time working at current facility, citizenship). It also assessed participation in WWP activities, job satisfaction, stress level, well-being, burnout and sources of stress.

Participation in WWP services was assessed using a question about each of the five activity types (health promotion, psychosocial and spiritual care, stress management and team building, therapeutic recreation, occupational health and safety). The number of times an individual had participated in each activity was assessed. Total number of activities was calculated by averaging the midpoint number from each response category across the five activity types.

Job satisfaction was assessed using the abridged Job Descriptive Index (JDI), ${ }^{23}$ a shortened form of the JDI, both psychometrically well-validated tools ${ }^{24}$ to measure satisfaction with work, co-workers, compensation, promotion opportunity and supervision. Respondents were asked to think about each job facet and respond to six adjectives/short phrases with 'yes', 'no' or 'cannot 
decide.' Responses were summed using the recommended cleaning and scoring procedures including eliminating 'straight line responses', dropping response with significant missing data and reverse-scoring negative phrases. The eight-item Job In General (JIG) scale was used to measure overall job satisfaction and cleaned in the same fashion. Occupational stress was assessed with the Stress in General (SIG) scale,,$^{25}$ using the same format as the JDI and JIG.

Psychological well-being was assessed with the General Health Questionnaire-12 (GHQ-12), a psychometrically well-validated, widely used tool, ${ }^{26}$ including in low-income settings. ${ }^{27}$ The GHQ comprises 12 items such as 'Have you recently been able to concentrate on what you're doing?' with responses on a four-point Likert-type scale (not at all, no more than usual, rather more than usual, much more than usual). Responses were summed using the author-recommended $0 / 0 / 1 / 1$ scoring.

Burnout was assessed using the 16-item Maslach Burnout Inventory-General Survey (MBI-GS), developed over 25 years ago ${ }^{28}$ show to have strong psychometric properties across settings and occupations. ${ }^{29-31}$ The GS version focuses on staff not providing direct human services and measures three subscales of exhaustion, cynicism and professional efficiency using five or six items each.

Sources of stress were measured using an investigator-adapted instrument from the 2006 Botswana Healthcare Worker Survey asking participants to rate whether 10 topics were sources of work-related stress on a five-point Likert scale (strongly agree, agree, not sure, disagree, strongly disagree). A response of 'strongly agree' or 'agree' was used to indicate stress.

\section{Statistics}

Data were entered and managed using Research Electronic Data Capture (REDcap) electronic data capture tools hosted at University of Washington. ${ }^{32}$ REDCap is a secure, web-based application designed to support data capture for research studies, providing an intuitive interface for validated data entry, audit trails for tracking data manipulation and export procedures, automated export procedures for seamless data downloads to common statistical packages and procedures for importing data from external sources. Data were exported to STATA V.14.2 for analysis.

Participants who did not respond to questions on WWP participation were removed from analysis. Descriptive statistics were generated to characterise the respondents' demographics, participation in WWP activities and psychosocial measures. Respondents were categorised into three WWP participation groups based on number of activities completed in the past year: 0 activities, 1-6 activities or $7+$ activities. Associations between demographics and WWP programme participation as well as psychosocial factors and WWP participation were analysed with $\mathrm{X}^{2}$ (categorical) and analysis of variance models (continuous). For psychosocial factors found to be associated with WWP participation, analysis of covariance models were built, controlling for associated demographics. Post hoc pairwise comparisons were conducted using the Bonferroni method. No sensitivity analyses were conducted.

\section{Ethics approval}

The evaluation was approved by the $\mathrm{MOH}$ Health Research and Development Committee Reference \#PPME: 13/18/1 Vol VIII (434), and non-research determination was received by the University of Washington's Internal Review Board Application \#45194EJ. It was conducted by the International Training and Education Centre for Health (I-TECH), which is a collaboration between the University of Washington and University of California, San Francisco under the guidance of a reference group of healthcare stakeholders which included representation from the Botswana Ministry of Health Departments of Corporate Services, HIV/AIDS Prevention and Care, Clinical Services and Public Health; the Seventh Day Adventist Mission Hospital in Kanye; Directorate of Public Service Management, Office of the President; the WHO and CDC Botswana.

\section{RESULTS}

Of the 1856 forms distributed, questionnaires were completed and returned by 1348 health workers, a response rate of $73 \%$. There were 30 respondents who did not answer questions on WWP participation and were removed from the analyses. Nearly two-thirds of respondents were female $(62.4 \%)$ and similar amounts were not married $(65.2 \%)$ (table 1 ). Of respondents, $2.9 \%$ were doctors, $29.2 \%$ were nurses, $27.4 \%$ were other professionals, $10.4 \%$ were administrative and $27.2 \%$ were support staff. The mean age was 40.0 years $(\mathrm{SD} \pm 9.9)$. About half worked in hospitals $(26.9 \%)$ or clinics with maternity $(24.9 \%)$.

Participants were split into roughly thirds of those who in the last year had participated in 0 WWP activities $(\mathrm{n}=387,29.4 \%), 1-6$ activities $(\mathrm{n}=513,38.9 \%)$ and seven or more activities $(n=418,31.7 \%)$. Among those who had participated in seven or more activities in the past year, psychosocial and spiritual care activities were the best attended, with $13.6 \%$ of participants attending seven or more in the last year, while only $2.8 \%$ of participants had attended the same quantity of occupational health and safety (OHSA) activities.

High participation in WWP activities was associated with older age, working longer in health services, working longer at a facility, being a doctor or other professional staff and being posted at hospitals and the DHMT. The strongest association was seen with facility type.

In unadjusted analyses, overall job satisfaction assessed by the JIG was significantly higher for health workers that participated in seven or more WWP activities, as compared with those who did not participate in any WWP activities $(p<0.001)$. There were similar findings with the JDI subscales related to satisfaction with work, supervision, promotion opportunities and pay, with the highest levels found among those participating in seven or more WWP activities (all $\mathrm{p} \leq 0.005)$. Psychological well-being measured by the GHQ-12 
Table 1 Demographic characteristics and workplace wellness programme (WWP) participation in the past year of 1318 WWP national survey participants

\begin{tabular}{|c|c|c|c|c|c|c|c|c|c|}
\hline \multirow[b]{3}{*}{ Characteristic } & \multirow{2}{*}{\multicolumn{2}{|c|}{ Total }} & \multicolumn{6}{|c|}{ WWP participation in last year } & \multirow[b]{3}{*}{$P$ values } \\
\hline & & & \multicolumn{2}{|c|}{0 Activities } & \multicolumn{2}{|c|}{ 1-6 Activities } & \multicolumn{2}{|c|}{ 7+ Activities } & \\
\hline & $\%$ & $n=1318^{*}$ & $\%$ & $n=387^{*}$ & $\%$ & $n=513^{*}$ & $\%$ & $n=418^{*}$ & \\
\hline Age (years) ${ }^{*}$ & & $39.9 \pm 9.9$ & & $39.9 \pm 10.1$ & & $39.2 \pm 9.6$ & & $40.9 \pm 10.1$ & 0.027 \\
\hline \multicolumn{10}{|l|}{ Gender } \\
\hline Female & 62.2 & 820 & 66.7 & 258 & 60.6 & 311 & 60.0 & 251 & 0.116 \\
\hline Male & 37.5 & 494 & 33.3 & 129 & 38.8 & 199 & 39.7 & 166 & \\
\hline \multicolumn{10}{|l|}{ Marital status } \\
\hline Not married & 65.2 & 859 & 65.6 & 254 & 66.9 & 343 & 62.7 & 262 & 0.364 \\
\hline Married & 33.8 & 445 & 33.1 & 128 & 32.2 & 165 & 36.4 & 152 & \\
\hline \multicolumn{10}{|c|}{ Number of children } \\
\hline 0 & 16.2 & 213 & 17.6 & 68 & 17.5 & 90 & 13.2 & 55 & 0.407 \\
\hline $1-2$ & 47.7 & 629 & 47.0 & 182 & 47.4 & 243 & 48.8 & 204 & \\
\hline $3-4$ & 27.6 & 364 & 28.9 & 112 & 26.3 & 135 & 28.0 & 117 & \\
\hline $5+$ & 7.2 & 95 & 5.9 & 23 & 7.0 & 36 & 8.6 & 36 & \\
\hline
\end{tabular}

Highest education completed

\begin{tabular}{|c|c|c|c|c|c|c|c|c|c|}
\hline $\begin{array}{l}\text { Less than high } \\
\text { school }\end{array}$ & 30.5 & 402 & 30.0 & 116 & 27.7 & 142 & 34.4 & 144 & 0.292 \\
\hline $\begin{array}{l}\text { Senior } \\
\text { secondary } \\
\text { school }\end{array}$ & 16.0 & 211 & 15.2 & 59 & 17.2 & 88 & 15.3 & 64 & \\
\hline $\begin{array}{l}\text { More than high } \\
\text { school }\end{array}$ & 50.5 & 666 & 50.6 & 196 & 52.4 & 269 & 48.1 & 201 & \\
\hline Botswana citizen & 93.8 & 1236 & 95.6 & 370 & 93.4 & 479 & 92.6 & 387 & 0.341 \\
\hline $\begin{array}{l}\text { Years worked in } \\
\text { health services* }\end{array}$ & & $11.9 \pm 9.0$ & & $11.7 \pm 8.7$ & & $11.2 \pm 8.7$ & & $12.9 \pm 9.4$ & 0.014 \\
\hline $\begin{array}{l}\text { Years worked in } \\
\text { facility* }\end{array}$ & & $3.1 \pm 1.3$ & & $2.9 \pm 1.3$ & & $3.1 \pm 1.3$ & & $3.2 \pm 1.3$ & 0.001 \\
\hline \multicolumn{10}{|l|}{ Cadre } \\
\hline Doctor & 2.9 & 38 & 2.1 & 8 & 2.9 & 15 & 3.6 & 15 & 0.001 \\
\hline Nurse & 29.2 & 385 & 35.1 & 136 & 29.6 & 152 & 23.2 & 97 & \\
\hline $\begin{array}{l}\text { Other } \\
\text { professional }\end{array}$ & 27.4 & 361 & 21.4 & 83 & 28.3 & 145 & 31.8 & 133 & \\
\hline Administrative & 10.4 & 137 & 10.3 & 40 & 12.3 & 63 & 8.1 & 34 & \\
\hline Support & 27.2 & 358 & 27.9 & 108 & 23.8 & 122 & 30.6 & 128 & \\
\hline \multicolumn{10}{|l|}{ Facility type } \\
\hline Hospital & 26.8 & 353 & 17.6 & 68 & 29.8 & 153 & 31.6 & 132 & $<0.001$ \\
\hline $\begin{array}{l}\text { Clinic with } \\
\text { maternity }\end{array}$ & 24.8 & 327 & 30.7 & 119 & 24.8 & 127 & 19.4 & 81 & \\
\hline $\begin{array}{l}\text { District health } \\
\text { management } \\
\text { team }\end{array}$ & 19.9 & 262 & 15.2 & 59 & 19.3 & 99 & 24.9 & 104 & \\
\hline $\begin{array}{l}\text { Clinic without } \\
\text { maternity }\end{array}$ & 17.6 & 232 & 24.0 & 93 & 15.0 & 77 & 14.8 & 62 & \\
\hline Health post & 8.8 & 116 & 10.3 & 40 & 8.6 & 44 & 7.7 & 32 & \\
\hline \multicolumn{10}{|c|}{ WWP activity participation $\ddagger(n)$} \\
\hline $\begin{array}{l}\text { Health } \\
\text { promotion }\end{array}$ & 1290 & $1.8 \pm 2.9$ & & 0 & & $1.4 \pm 1.3$ & & $4.0 \pm 4.0$ & \\
\hline
\end{tabular}


Table 1 Continued

\begin{tabular}{|c|c|c|c|c|c|c|c|c|c|}
\hline \multirow[b]{3}{*}{ Characteristic } & \multirow{2}{*}{\multicolumn{2}{|c|}{ Total }} & \multicolumn{6}{|c|}{ WWP participation in last year } & \multirow[b]{3}{*}{$P$ values $†$} \\
\hline & & & \multicolumn{2}{|c|}{0 Activities } & \multicolumn{2}{|c|}{ 1-6 Activities } & \multicolumn{2}{|c|}{ 7+ Activities } & \\
\hline & $\%$ & $n=1318^{*}$ & $\%$ & $\mathrm{n}=387^{*}$ & $\%$ & $n=513^{*}$ & $\%$ & $n=418^{*}$ & \\
\hline $\begin{array}{l}\text { Therapeutic } \\
\text { recreation }\end{array}$ & 1278 & $0.9 \pm 2.5$ & & 0 & & $0.4 \pm 0.8$ & & $2.5 \pm 3.8$ & \\
\hline $\begin{array}{l}\text { Occupational } \\
\text { health and } \\
\text { safety }\end{array}$ & 1288 & $0.7 \pm 2.0$ & & 0 & & $0.4 \pm 0.8$ & & $1.9 \pm 3.2$ & \\
\hline
\end{tabular}

${ }^{*} \mathrm{~N}(\%)$ may not be equal to total due to missing data or rounding. Percentages are calculated using missing data. $\dagger P$ value calculated from $X^{2}$ test for categorical variables and analysis of variance for continuous variables. $\ddagger$ Mean \pm SD.

did not differ significantly by level of WWP participation. However, levels of stress from the SIG as well as measures of exhaustion and cynicism from the MBI were significantly lower among those with high participation in WWP activities. All associations remained the same in analyses controlled for age, cadre, and facility type, except for the MBI subscale of cynicism, which became non-significant. Post hoc analyses of differences between groups are presented in table 2 .
The three most commonly reported sources of stress were shortages of staff $(78.0 \%)$, insufficient resources and supplies $(76.7 \%)$ and too much work $(72.7 \%)$ (table 3). Compared to the 2006 survey, fewer participants in 2014 indicated each category was a source of stress. The only exception was for 'non-supportive supervisors' which saw a slight increase from 58\% in 2006 to $59.5 \%$ in 2013.

Table 2 Association of job satisfaction, stress, well-being and burnout with workplace wellness programme (WWP) participation in the past year among 1291 WWP national survey participants

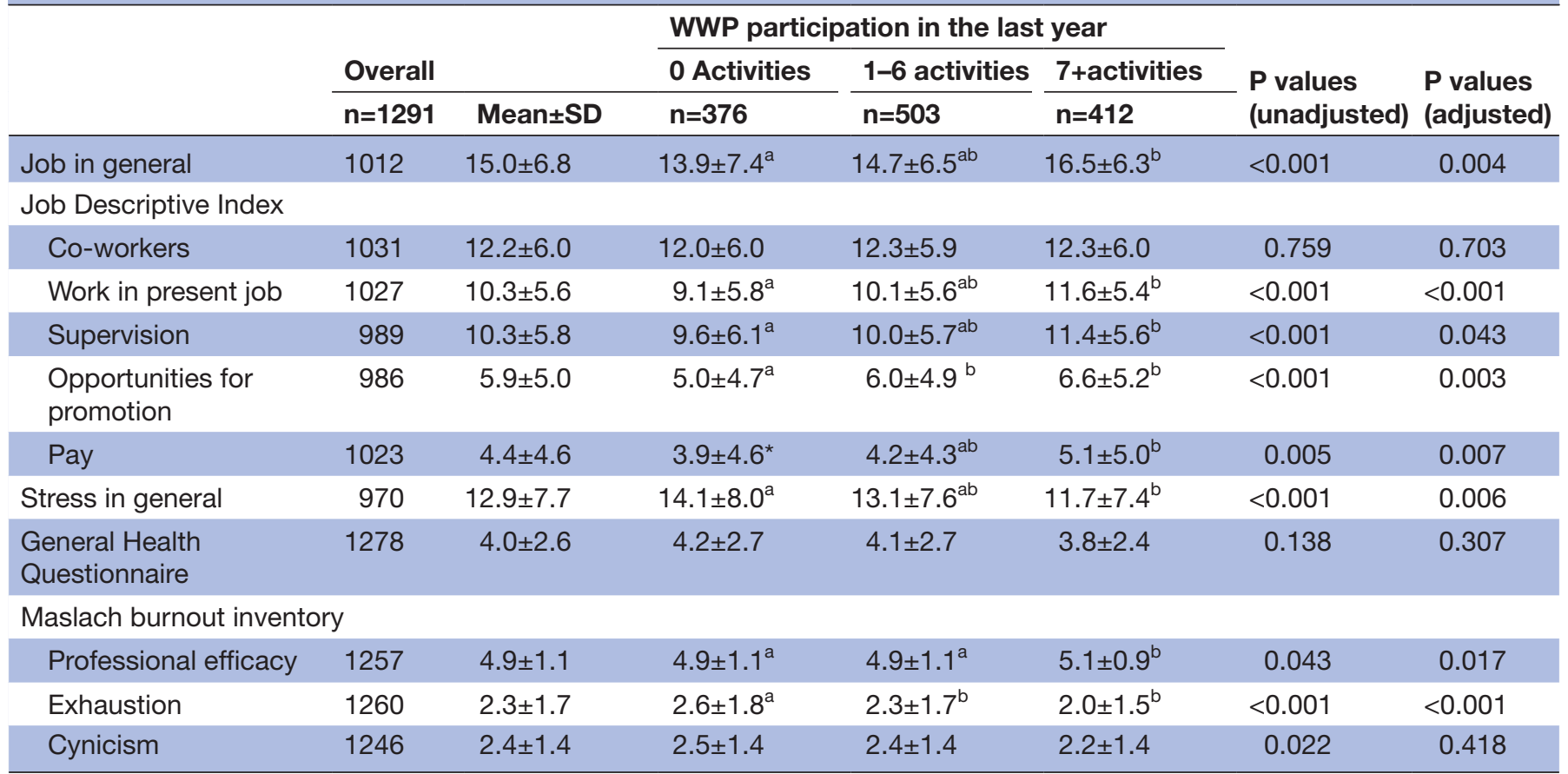

All outcome variables were continuous and tested with one-way analysis of variances. Adjusted analyses used analysis of covariances, controlling for age (continuous), cadre (five levels) and facility type (five levels). Mean values with different superscript letters are significantly different using Bonferroni pairwise comparisons. 
Table 3 Comparison of sources of stress between participants in the 2013 workplace wellness programme national survey and 2006 healthcare worker survey

\begin{tabular}{|c|c|c|c|c|}
\hline \multirow{2}{*}{$\begin{array}{l}\text { Sources of stress } \\
\text { (agree/strongly agree) }\end{array}$} & \multicolumn{2}{|l|}{2013} & \multicolumn{2}{|c|}{2006} \\
\hline & $\%$ & $(n=1313)$ & $\%$ & $(n=223)$ \\
\hline Shortage of staff & 78.0 & 1051 & 91 & 201 \\
\hline $\begin{array}{l}\text { Insufficient resources } \\
\text { and supplies }\end{array}$ & 76.7 & 1034 & - & - \\
\hline Too much work & 72.7 & 980 & 88 & 196 \\
\hline $\begin{array}{l}\text { Not being appreciated } \\
\text { for the work I do }\end{array}$ & 64.1 & 864 & 76 & 169 \\
\hline $\begin{array}{l}\text { Non-supportive } \\
\text { supervisors }\end{array}$ & 59.5 & 802 & 58 & 129 \\
\hline $\begin{array}{l}\text { Balancing demands of } \\
\text { work and family }\end{array}$ & 51.3 & 691 & - & - \\
\hline $\begin{array}{l}\text { Providing care for many } \\
\text { patients }\end{array}$ & 49.0 & 660 & 85 & 190 \\
\hline $\begin{array}{l}\text { Providing care for many } \\
\text { patients with HIV/AIDS }\end{array}$ & 42.3 & 570 & 76 & 169 \\
\hline $\begin{array}{l}\text { Providing support for } \\
\text { relatives of patients }\end{array}$ & 41.3 & 557 & 55 & 123 \\
\hline $\begin{array}{l}\text { Conflict with co- } \\
\text { workers }\end{array}$ & 39.7 & 535 & - & - \\
\hline
\end{tabular}

\section{DISCUSSION}

Data from this nationally representative survey of health workers in Botswana found that participation in workplace wellness activities was associated with higher levels of job satisfaction and professional efficacy. Participation in workplace wellness activities was also associated with lower levels of stress and exhaustion. To the authors' knowledge, this is the first report of the effectiveness of a national workplace health promotion initiative for public health workers in middle-income or low-income countries. Health workers were more likely to participate in WWP activities if they were of older age, worked longer in health services, worked longer at a facility, were a doctor or other professional staff or were posted at hospitals and the DHMT. This last and strongest association was possibly due to greater access to activities at these sites.

While there is a large body of literature on health-promotion activities in high-income countries, workplace health promotion programmes in middle-income or low-income countries have been reported less frequently, ${ }^{13} 2033$ particularly in healthcare settings. ${ }^{34}$ Much of the existing research comes from the Healthy Company Index, which was developed by a large health insurer in South Africa to promote healthy lifestyles among insurees. ${ }^{17-20}$ Data from this programme indicate that WWPs are positively associated with employee health. Specifically, employees at companies providing health promotion facilities are more likely to meet the guidelines for physical activity and daily consumption of fruits and vegetables. ${ }^{18}$ The Maslach Burnout Model indicates that burnout is a result of chronic stress ${ }^{1}$; however, a recent literature review indicates that the interplay between workplace stress, burnout, job satisfaction and general health is not well understood. ${ }^{35}$ Thus, the mechanism by which WWPs may improve well-being is unclear.

Additional research from the Healthy Company Index shows that leadership support of WWPs influences the provision of health promotion facilities and policies, resulting in higher employee well-being and increased perceived organisational commitment to well-being. ${ }^{19}$ The authors argue based on social exchange theory (SET), ${ }^{36}$ WWPs may have benefits beyond those created by their direct use. Even employees who do not participate in the programmes may still benefit through the perception that the organisation they work cares about their health. The importance of enacting such programmes and policies is an important implication for policymakers charged with caring for the public health workforce.

The data on sources of stress can be directly compared with the 2006 survey conducted before the implementation of the WWP. In the recent study, fewer respondents reported providing care for HIV/AIDS (42\% vs $76 \%$ ), caring for many patients $(49.0 \%$ vs $85 \%)$, too much work $(72.7 \%$ vs $88 \%)$ and staff shortages $(78 \%$ vs $91 \%)$ as a source of stress. ${ }^{37}$ These results are encouraging, as they suggest there have been improvements in reducing workplace stress. However, it is unclear what these changes are attributable to, including increased familiarity with HIV/AIDS, more straightforward treatment regimens, programmes like WWP, increased human resources in the health field or other changes. In addition, the continuing high level of staff shortages and slight rise in non-supportive supervisors $(59.5 \%$ vs $58 \%)$ is notable, as other research in the region highlights that stress related to staff issues may be a key factor for burnout among healthcare professionals. ${ }^{38}$

These conclusions must be interpreted within the context of this study design. As a cross-sectional survey, it is impossible to determine the direction of causality. Participation in workplace wellness activities may have increased feelings of job satisfaction and efficacy and decreased stress and burnout. However, it is equally plausible that individuals who felt more satisfied and efficacious and less stressed and burnt out were more likely to participate in workplace wellness activities. Strengths of this study include a multilevel random sampling methodology, use of previously validated scales and a relatively high response rate $(73 \%)$. Given the representative nature of the study, the results are likely generalisable to public health workforces in other low-income and middle-income countries.

The health systems of middle-income and low-income countries are facing a particularly important and challenging time. There has been marked progress towards key international initiatives including the United Nations Development Programme sustainable development goals, the UNAIDS 90-90-90 HIV treatment goals and the WHO initiatives for the elimination of mother to child transmission of HIV and syphilis. However, achievement of these ambitious goals requires intensified efforts. This can create tense environments for healthcare workers, leading high levels of stress, burnout and job dissatisfaction. This study has highlighted WWPs 
as a potential avenue to support these vital staff. Further, it is possible that providing these types of activities may facilitate higher job satisfaction and lower levels of stress and burnout. Further, SET reinforces the implications of having such programmes formally codified as organisational policy. Piloting of similar programmes in similar strained healthcare systems could be extremely helpful in the attainment of key international public health and development goals.

Contributors JHL and NJK prepared the first draft, finalised the report based on feedback from other authors and analysed and interpreted the data. JHL, MM, HM, SM, B-wS and GOM helped provide overall guidance to the conduct of the study and were involved in the origination and development of the concept of the study. All authors reviewed the manuscript and provided comments.

Funding This work was supported by the President's Emergency Plan for AIDS Relief (PEPFAR), through funding to the University of Washington and I-TECH from the US Department of Health and Human Services, Health Resources and Services Administration (HRSA) Global HIV/AIDS Bureau, Cooperative Agreement \#U91HA06801.

\section{Competing interests None declared.}

Patient consent Not required.

Ethics approval University of Washington's Internal Review Board.

Provenance and peer review Not commissioned; externally peer reviewed.

Data sharing statement Extra data are available by emailing Dr Ledikwe @ ledikwe@uw.edu.

Open Access This is an Open Access article distributed in accordance with the Creative Commons Attribution Non Commercial (CC BY-NC 4.0) license, which permits others to distribute, remix, adapt, build upon this work non-commercially, and license their derivative works on different terms, provided the original work is properly cited and the use is non-commercial. See: http://creativecommons.org/ licenses/by-nc/4.0/

(C) Article author(s) (or their employer(s) unless otherwise stated in the text of the article) 2018. All rights reserved. No commercial use is permitted unless otherwise expressly granted.

\section{REFERENCES}

1. Maslach C, Schaufeli WB, Leiter MP. Job burnout. Annu Rev Psychol 2001;52:397-422.

2. Felton JS. Burnout as a clinical entity-its importance in health care workers. Occup Med 1998;48:237-50.

3. Silverman DC. Psychosocial impact of HIV-related caregiving on health providers: a review and recommendations for the role of psychiatry. Am J Psychiatry 1993;150:705-12.

4. Demmer C. Burnout: the health care worker as survivor. AIDS Read 2004:14:522-523, 528-530, 535-527.

5. Kerr ZY, Miller KR, Galos D, et al. Challenges, coping strategies, and recommendations related to the HIV services field in the HAART era: a systematic literature review of qualitative studies from the United States and Canada. AIDS Patient Care STDS 2013;27:85-95.

6. UNAIDS: 90-90-90 An ambitious treatment target to help end the AIDS epidemic, 2014.

7. Government of Botswana. Botswana AIDS Impact Survey IV (BAIS IV), 2012.

8. Botswana Ministry of Health. Wellness program for health workers (WHW): implementation plan 2006-2009, 2006

9. Ledikwe JH, Semo BW, Sebego M, et al. Implementation of a National Workplace Wellness Program for Health Workers in Botswana. J Occup Environ Med 2017;59:867-74.

10. Government of Botswana. Botswana workplace wellness program operational guidelines. Gaborone, Botswana: Ministry of Health 2007.

11. Baicker K, Cutler D, Song Z. Workplace wellness programs can generate savings. Health Aff 2010;29:304-11.

12. Goetzel RZ, Henke RM, Tabrizi M, et al. Do workplace health promotion (wellness) programs work? J Occup Environ Med 2014;56:927-34.
13. Kolbe-Alexander TL, Proper KI, Lambert EV, et al. Working on wellness (WOW): a worksite health promotion intervention programme. BMC Public Health 2012;12:372.

14. Astrella JA. Return on investment: evaluating the evidence regarding financial outcomes of workplace wellness programs. J Nurs Adm 2017;47(7-8):379-83.

15. Kaspin LC, Gorman KM, Miller RM. Systematic review of employersponsored wellness strategies and their economic and health-related outcomes. Popul Health Manag 2013;16:14-21.

16. Howarth A, Quesada J, Mills PR. A global, cross cultural study examining the relationship between employee health risk status and work performance metrics. Ann Occup Environ Med 2017;29:17.

17. Milner K, da Silva R, Patel D, et al. How do we measure up? A comparison of lifestyle-related health risk factors among sampled employees in South African and UK companies. Glob Health Promot 2016:175797591665634

18. Kolbe-Alexander T, Greyling M, da Silva R, et al. The relationship between workplace environment and employee health behaviors in a South African workforce. J Occup Environ Med 2014;56:1094-9.

19. Milner K, Greyling M, Goetzel R, et al. The relationship between leadership support, workplace health promotion and employee wellbeing in South Africa. Health Promot Int 2015;30:514-22.

20. Patel D, Goetzel RZ, Beckowski M, et al. The Healthiest Company Index: a campaign to promote worksite wellness in South Africa. $J$ Occup Environ Med 2013;55:172-8

21. Conradie CS, van der Merwe Smit E, Malan DP. Corporate health and wellness and the financial bottom line: evidence from South Africa. $J$ Occup Environ Med 2016;58:e45-53.

22. Government of Botswana. National Health Service situational analysis report, 2009

23. Stanton JM, Sinar EF, Balzer WK, et al. Development of a compact measure of job satisfaction: the abridged job descriptive index. Educ Psychol Meas 2002;62:173-91.

24. Kinicki AJ, Mckee-Ryan FM, Schriesheim CA, et al. Assessing the construct validity of the job descriptive index: a review and metaanalysis. J Appl Psychol 2002;87:14-32.

25. Stanton JM, Balzer WK, Smith PC, et al. A general measure of work stress: the stress in general scale. Educ Psychol Meas 2001;61:866-88.

26. Jackson C. The general health questionnaire. Occup Med 2007;57.

27. Ali GC, Ryan G, De Silva MJ. Validated screening tools for common mental disorders in low and middle income countries: a systematic review. PLoS One 2016;11:e0156939.

28. Schaufeli WB, Greenglass ER. Introduction to special issue on burnout and health. Psychol Health 2001;16:501-10.

29. Poghosyan L, Aiken LH, Sloane DM. Factor structure of the Maslach burnout inventory: an analysis of data from large scale crosssectional surveys of nurses from eight countries. Int J Nurs Stud 2009;46:894-902.

30. Worley J, Vassar M, Wheeler D, et al. Factor structure of scores from the Maslach Burnout Inventory: a review and meta-analysis of 45 exploratory and confirmatory factor-analytic studies. Educ Psychol Meas 2008;68:797-823.

31. Langballe EM, Falkum E, Innstrand ST, et al. The factorial validity of the Maslach Burnout Inventory-general survey in representative samples of eight different occupational groups. J Career Assess 2006;14:370-84.

32. Harris PA, Taylor R, Thielke R, et al. Research electronic data capture (REDCap) - a metadata-driven methodology and workflow process for providing translational research informatics support. J Biomed Inform 2009;42:377-81.

33. Yassi A, O'Hara LM, Lockhart K, et al. Workplace programmes for HIV and tuberculosis: a systematic review to support development of international guidelines for the health workforce. AIDS Care 2013;25:525-43.

34. Basson HA, Roets L. Workplace wellness for HIV/AIDS-affected nurses in South Africa. Br J Nurs 2013;22:38-44.

35. Khamisa N, Peltzer K, Oldenburg B. Burnout in relation to specific contributing factors and health outcomes among nurses: a systematic review. Int J Environ Res Public Health 2013;10:2214-40.

36. Cropanzano R, Mitchell MS. Social exchange theory: an interdisciplinary review. J Manage 2005;31:874-900.

37. Botswana Ministry of Health, and ITECH-Botswana. "Evaluation of the botswana ministry of health's workplace wellness programme to improve implementation, utilization, impact and sustainability", 2014.

38. Khamisa N, Oldenburg B, Peltzer K, et al. Work related stress, burnout, job satisfaction and general health of nurses. Int $J$ Environ Res Public Health 2015;12:652-66. 